[CONTRIbUtions From THE HaVeMeyer Laboratories of Columbia [NIVERSITY, No. 26.]

\title{
THE DIRECT SYNTHESIS OF KETODIHYDROQUINAZOLINS FROM ORTHOAMINO ACIDS.
}

By Marston Taylor Bogert and Augest Henry Gotthelf.

Received Iune 28, rgo0.

\begin{abstract}
$\triangle \mathrm{S}$ announced in our preliminary paper on this subject, ${ }^{2}$ ketoA dihydroquinazolins (or oxyquinazolins) can readily be obtained by the action of nitriles upon orthoamino acids under conditions of heat and pressure. The present paper is confined to a discussion of the 2-methyl-4-ketodihydroquinazolin. Many others have been prepared and studied, and will form the subjects of later communications.
\end{abstract}

For convenience, throughout this article we have called our compound a "quinazolon" although we do not intend thereby to indicate any preference for the keto form as compared with the tautomeric oxyquinazolin form. The numbering for the quinazolin nucleus is that first suggested by $\mathrm{Paal}$ and Busch."

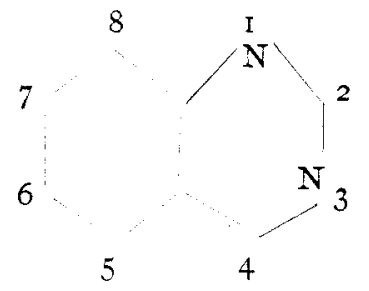

Weddige the discoverer of this 2-methyl-4-ketodihydroquinazolin, obtained it from orthoacetaminobenzamide by fusion, by solution in alkalies with subsequent precipitation with acid, or by long boiling with water; also, by heating ethylorthoacetaminobenzoate to $160^{\circ} \mathrm{C}$. with strong aqueous ammonia. Bischler and Burkart ${ }^{5}$ accomplished the same result by fusing the ammonium salt of orthoacetaminobenzoic acid, while Niementowski ${ }^{6}$ prepared it by heating together anthranilic acid and acetamide.

1 Read before the joint meeting of the American Chemical society and section $C$ of the American Association for the Advancement of science, June 25, 1900.

2 This Journal, 32, 129.

3 Ber, d. chem. Ges., 22, 2684.

4. prakt. Chem. [2], 31, 124; 36, 143 .

- Ber. d. chem. Ges., 26, 1350.

b). prakt. Chem. [2], 51, 564. 
The syntheses of Weddige and Bischler are practically identical, both depending upon the formation of orthoacetaminobenzamide, from which the quinazolon results by loss of water. The course of Niementowski's synthesis is probably similar in the main, the following reactions being suggested in explanation:

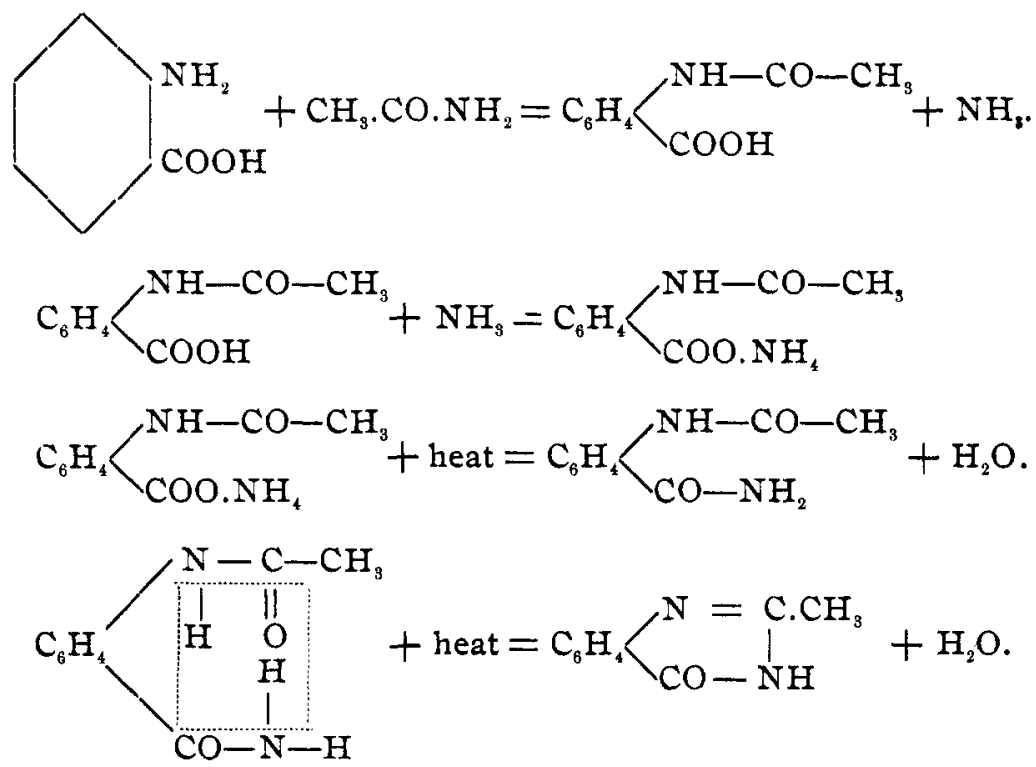

The first of these reactions seems probable when one remembers that acetanilide results from heating together aniline and acetamide, and that, with other amines, acetamide likewise yields the amide of the higher acid. The remaining reactions are then the same as in Bischler's synthesis.

In all these syntheses there is an interesting point which should not be overlooked, and that is the manner in which the water splits out in the production of the quinazolon. By an examination of the formulas, it will be seen that this may occur in two different ways, one being a lactam condensation, the other equivalent to a lactim condensation, resulting in the production of two separate and distinct isomers, as follows : 
524 MARSTON T. BOGERT AND AUGUST H. GOTTHELF.

(I)
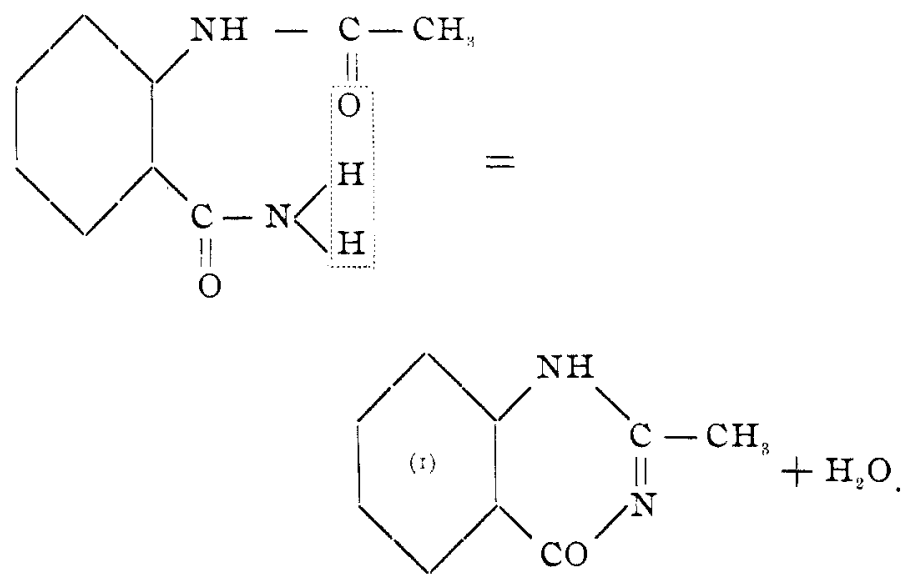

Pheno-2-methylhexadiazen(2)on(4).

(II)
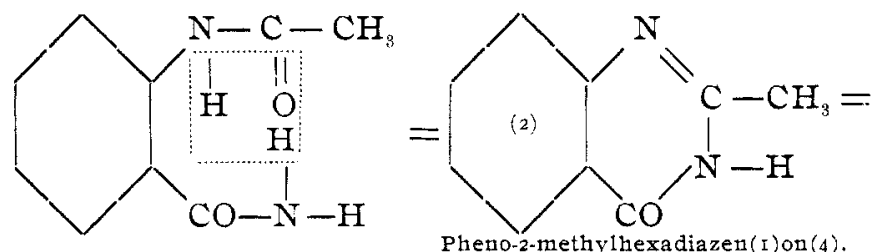

Pheno-2-methylhexadiazen(I) on (4).

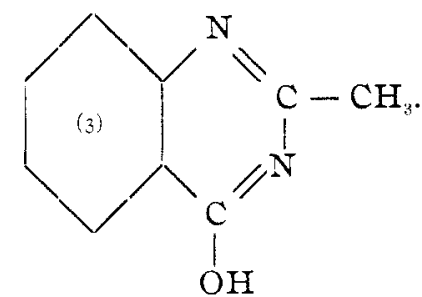

Pheno-2-methylhexadiazadien $(r, 3)$ on (4) or 2, methy $1-4$-oxyquinazolin.

By a series of interesting reactions, Weddige proved his product to be (2) or (3), and the condensation, therefore, to have followed reaction (II). He did not, however, determine whether the compound appeared preferably in its keto or enol form, in his furtherstudies of its properties. The products obtained by Bischler, by Niementowski, and by ourselves are identical in all respects with this compound of Weddige's, and the isomer represented by ( $I$ ) is still unknown. 
The conditions of our experiments resulting in the production of a quinazolon from anthranilic acid and nitriles were such that the first product of the reaction might be either a secondary amide, due to a condensation of the carboxyl and cyanogen groups or a transposition of groups might occur, giving anthranilic nitrile and acetic acid. ${ }^{2}$ In the first case then, as our substance is identical with Weddige's, the reactions would be as follows :<smiles>COC(=O)NOC(=O)C(N)c1ccccc1</smiles>

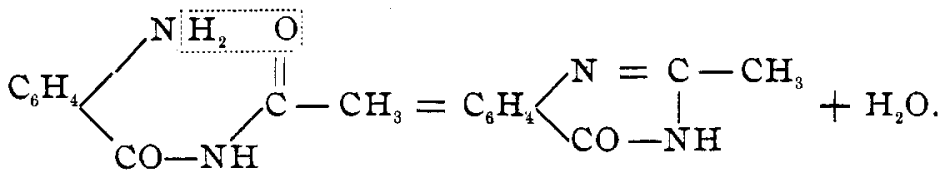

and not thus

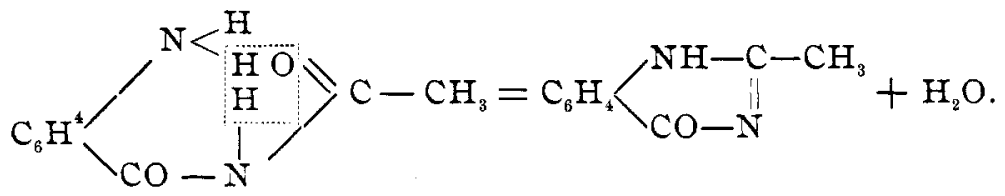

If this really represents the course of the reaction, it presents one or two interesting features. First, the elimination of water cannot here occur in the way described by Weddige, or an isomer would result with the double bond at (2) instead of at (I) as already mentioned. In regard to this point, however, it should be noted that this reaction is not exactly comparable with Weddige's, since in one case the condensation occurs with an aminic group, and in the other case with an amidic one. Another feature in which this synthesis differs from those already mentioned is in the position of the condensing acyl group, which here appears on the acid chain instead of in the amino group.

In later experiments, where acetic anhydride was present, the reactions would be similar:

1 Compare Gautier: Compt. rend., 67, I255; and Colby and Dodge: $A m$. Chem. I., I3, I. 
$\mathrm{C}_{6} \mathrm{H}_{4}\left\langle\mathrm{COOH}_{\mathrm{NH}_{2}}^{+}+\left(\mathrm{CH}_{3} \cdot \mathrm{CO}\right)_{2} \mathrm{O}=\right.$

$\mathrm{C}_{6} \mathrm{H}_{4}\left\langle\frac{\mathrm{NH}-\mathrm{CO}-\mathrm{CH}_{3}}{\mathrm{COH}}+\mathrm{CH}_{3} \cdot \mathrm{COOH} ;\right.$

$\mathrm{C}_{6} \mathrm{H}_{4}<\mathrm{NOOH}-\mathrm{CO}-\mathrm{CH}_{3}+\mathrm{CH}_{3} \cdot \mathrm{CN}=$<smiles>CCOC(=O)N[C@H](C(=O)OC)c1ccccc1</smiles>

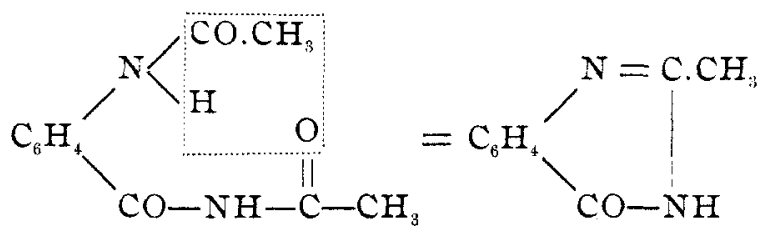

$+\mathrm{CH}_{3} \cdot \mathrm{COOH}$.

Although, in this case the possibility is not excluded of the reaction following the line indicated by Weddige :<smiles>COC(=O)NOC(=O)NCCC(=O)O</smiles>

In proof of the above reaction, acetylanthranilic acid was heated in a sealed tube with acetonitril, and the same quinazolon obtained.

Another course which may be followed by the reaction is this:

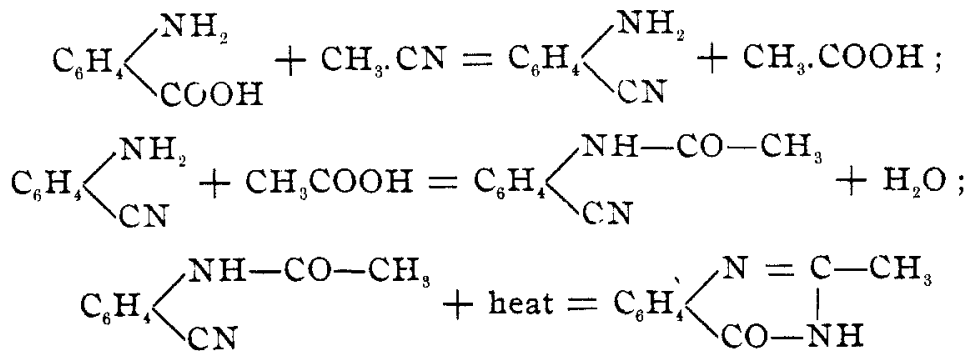

The quinazolon being more stable at high temperatures than the anthranilic nitrile might cause such a rearrangement, but 
Saemann, ${ }^{1}$ who examined anthranilic nitrile, together with its acetyl and benzoyl derivatives, observed no such change. The production of anthranilic nitrile as the first phase of the reaction is more in accord with the results obtained by Colby and Dodge, but in some experiments carried out by us with the meta- and paraminobenzoic acids and acetonitrile we have been unable to isolate any aminobenzonitriles, although similar experiments with the three nitrobenzoic acids readily yielded the corresponding nitrobenzonitriles.

In our first experiments equal molecules of acid and nitrile were used, but in all of the later ones acetic anhydride was also added, and the reaction will then be slightly different:<smiles>COC(=O)CC(N)C(=O)O</smiles>

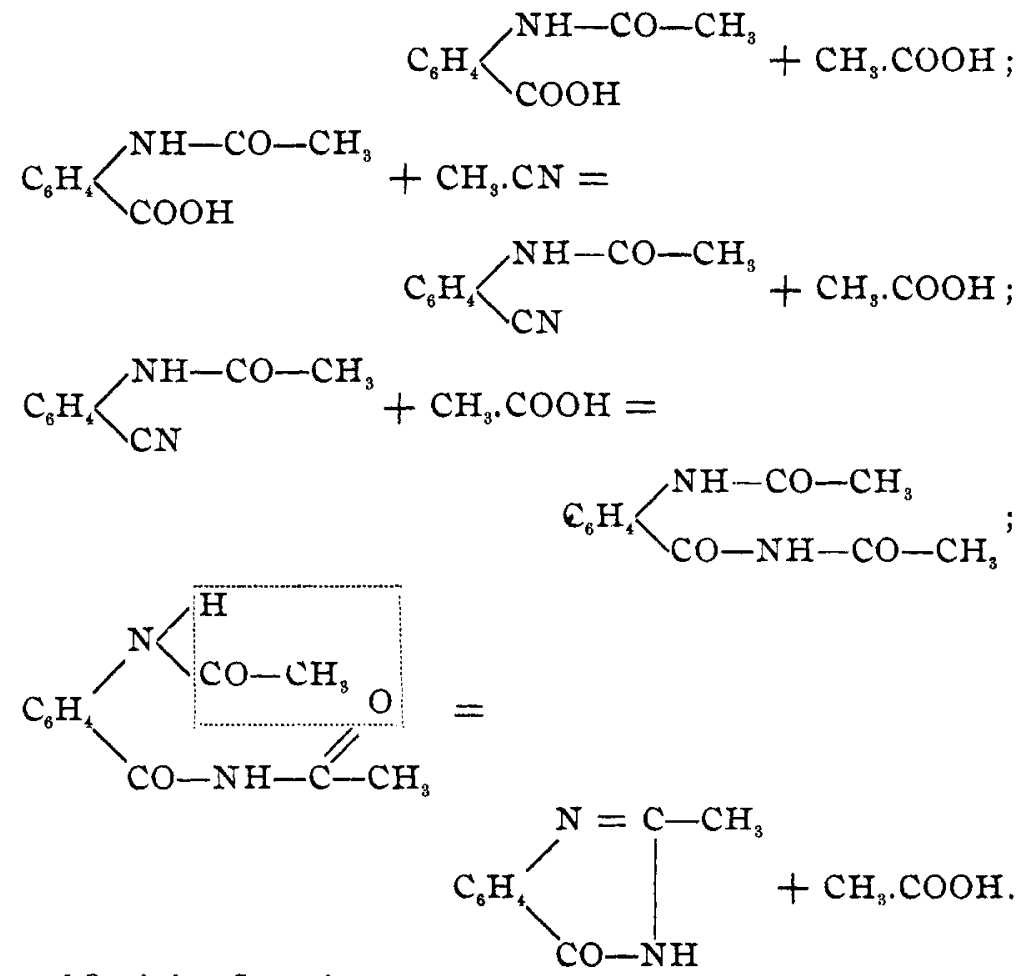

1 Ber. $d_{i}$ chem. Ges., 29, 63I. 
We, therefore, prepared some acetylanthranilic nitrile and heated it with acetic anhydride in a sealed tube, the result being the same quinazolon as before. Such a reaction is not likely to have taken place in the tubes where no acetic anhy. dride was used, for there would have been no excess of acetic acid to combine with the nitrile for the production of the secondary amid, the acetic acid reacting first, of course, with the amino group.

To sum up then, it seems most probable to us that the course of the reactions is as follows:

I. In Absence of Acetic Anhydride.-Condensation of the carboxyl and cyanogen groups to a secondary amide, which passes into the quinazolon by loss of water.

2. In Presence of Acetic Anhydride.-Production of acetylanthranilic acid, with subsequent combination of carboxyl and cyanogen groups, the resulting secondary amide yielding the quinazolon by loss of acetic acid.

EXPERIMENTAL PART.

Synthesis of 2-methyl-4-ketodihydroquinazolin from anthranilic acid and acetonitrile.

Anthranilic Acid and Acetonitrile.-One molecule of anthranilic acid and 2 or 3 molecules of acetonitrile were heated together in a sealed tube for six hours at $200^{\circ}-210^{\circ} \mathrm{C}$. The tube then contained a crystalline mass wet with a dark liquid, and when opened evolved carbon dioxide with considerable force. The mass was extracted with ether, and the ether solution filtered. On driving off the ether from the filtrate a brown oil remained together with a small amount of a crystalline substance. This oil was driven over with steam and found to be aniline, while the crystalline substance was identified as acetanilide. The carbon dioxide and aniline were the ustual decomposition products of the anthranilic acid, the acetanilide being formed by a secondary reaction between aniline and acetic acid or aniline and acetamide.

The residue insoluble in ether consisted of needles which, recrystallized from water and bone-blacked, melted at $232^{\circ}-233^{\circ}$ C. $\left(238^{\circ}-239^{\circ} \mathrm{C}\right.$. corr. $)$. These crystals were insoluble in cold water, soluble in hot, and partly soluble in hot chloroform. The 
aqueous solution was acid to litmus, but did not decompose sodium carbonate solution, or dissolve freshly precipitated silver oxide when boiled with it. They readily dissolved in concentrated potassium hydroxide solution, but underwent no decomposition when the solution was boiled; but when this same alkaline solution was boiled with excess of concentrated hydrochloric acid and then cooled, long transparent needles of a hydrochloric acid salt were obtained, which sublimed before melting and gave the free base again (m. p. $232^{\circ} \mathrm{C}$.) when treated with sodium carbonate solution. An aqueous solution of the free base gave the following reactions: with copper sulphate solution, a light blue precipitate; with silver nitrate solution, a white precipitate; with stannous chloride solution, a gelatinous precipitate, dissolving on heating and separating out in needles on cooling; with cobalt nitrate solution, a voluminous curdy precipitate, blue in presence of any excess of alkali ; with mercuric chloride solution, a curdy white precipitate; with lead acetate solution, a curdy white precipitate. An aqueous solution of the hydrochloric acid salt gave a dark yellow precipitate with neutral potassium chromate, and an orange-red one with platinum chloride.

The free base crystallizes from water in transparent prisms or needles, carrying I molecule of water of crystallization which they readily lose at $100^{\circ} \mathrm{C}$. An analysis of the crystals, dried at $100^{\circ} \mathrm{C}$. gave the following results :

I. 0.1582 gram substance gave 0.3904 gram carbon dioxide, and 0.07 I I gram water.

II. 0.1584 gram substance gave 0.3898 gram carbon dioxide, and 0.0722 gram water.

III. 0.1466 gram substance gave 0.3628 gram carbon dioxide, and 0.0666 gram water.

IV. 0.I6I 3 gram substance gave $26 \mathrm{cc}$. nitrogen at $24^{\circ} \mathrm{C}$. and $756 \mathrm{~mm}$.

V. 0.1468 gram substance gave $23.8 \mathrm{cc}$. nitrogen at $22.5^{\circ} \mathrm{C}$. and $75^{\circ} \mathrm{mm}$.

\begin{tabular}{|c|c|c|c|c|c|c|}
\hline & $\begin{array}{l}\text { Calculated for } \\
\mathrm{C}_{9} \mathrm{H}_{8} \mathrm{~N}_{2} \mathrm{O} \text {. }\end{array}$ & I. & II. & $\begin{array}{l}\text { Found. } \\
\text { III. }\end{array}$ & Iv. & \\
\hline $\begin{array}{l}\text { Carbon } \ldots \ldots \ldots \ldots \ldots \\
\text { Hydrogen } \ldots \ldots \ldots \ldots\end{array}$ & $\therefore \quad 67.50$ & $\begin{array}{r}67.30 \\
4.99\end{array}$ & $\begin{array}{r}67 . \mathrm{II} \\
5.06\end{array}$ & 67.49 & $\ldots$ & \\
\hline Nitrogen ................ & $\begin{array}{r}5.00 \\
. \quad \\
17.50\end{array}$ & $\begin{array}{l}4.99 \\
\cdots .\end{array}$ & $\ldots$ & 5.04 & 17.97 & I8.07 \\
\hline Oxygen...$\ldots \ldots \ldots$ & ․ 10.00 & $\cdots \cdot$ & $\cdots$ & $\cdots \cdot$ & $\cdots$ & \\
\hline
\end{tabular}


The molecular weight was also determined by the freezingpoint method, using glacial acetic acid as the solvent:

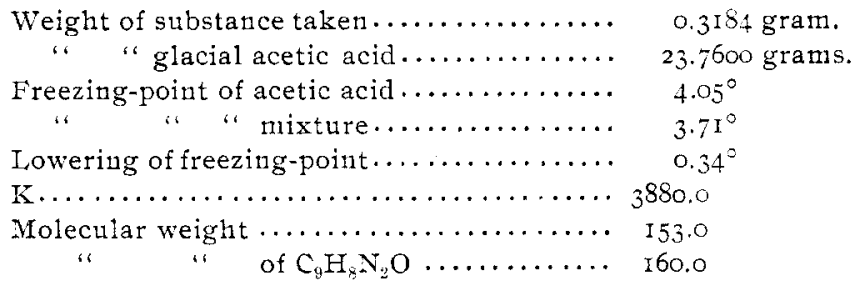

The substance is hence identical with the 2-methyl-4-ketodihydroquinazolin of Weddige, Bischler, and Niementowski.

One of the first difficulties encountered in this synthesis is the tendency of the anthranilic acid to break up into carbon dioxide and aniline, and we have not been able as yet to overcome this entirely. Very gradual heating of the tube contents, even when long continued, did not appear to give any better yield than direct heating at $200^{\circ}-210^{\circ} \mathrm{C}$. for six or eight hours. The water split off in the reaction was also found to exert a most harmful infuence upon the products, "causing decomposition and the formation of much tar. The use of an excess of acetonitrile improved the yield somewhat, and the addition of acetic anhydride was found particularly beneficial in this respect. By using nearly enough anhydride to take up all the water split off, the yield was nearly doubled, being brought up to 45 per cent. of the theory, while the tube contents were invariably light colored and free from tar.

Syntheses of Bischler and Burkart, and of Niementowski.-For purposes of comparison some 2-methyl-4-ketodihydroquinazolin was prepared by the method of Bischler and Burkart, and of Niementowski.

Bischler and Burkart's Synthesis.-Acetylanthranilic acid was neutralized with ammonia, the solution evaporated to crystals, and the product recrystallized. Fusion of these crystals for twenty minutes gave a yield of the quinazolon amounting to about 25 per cent. of the weight of the acetylanthranilic acid used. Dehoff. ${ }^{1}$ who was the first to suggest this method, abandoned it as unsatisfactory, but his difficulty seems to have been in getting a pure anthranilic acid to start with.

1 J.prakt. Chem. [2], 42, 347. 
Niementowski's Synthesis. - This investigator states that by fusing together acetamide and anthranilic acid for six to eight hours at $\mathrm{r} 35^{\circ}-155^{\circ} \mathrm{C}$. a yield of quinazolon may be obtained equal to half the weight of the anthranilic acid used. Our experience indicated that twenty-four hours' heating at this temperature was necessary to remove all ammonia, and the yield of quinazolon was only about half that given by Niementowski. By treating the melt with ether the quinazolon remains insoluble and can thus be separated and recrystallized. In the ethereal washings we have isolated, in addition to acetanilide, a substance crystallizing from water in flat needles with jagged edges, and melting at $190^{\circ}-191^{\circ} \mathrm{C}$. ( $194^{\circ}-195^{\circ} \mathrm{C}$. corr.). This melting-point could not be altered by repeated crystallizations, from water, and the substance cannot therefore be impure quinazolon. With metallic potassium or sodium the presence of nitrogen in this substance is easily demonstrated, but boiling with concentrated potassium hydroxide solution produces no ammonia, aniline, or other primary amine, for no isonitrile odor could be detected after the addition of chloroform, and it does not seem possible, therefore, that the compound can be amidic in character. That it probably represents an intermediate step in the reaction, however, is clearly shown by the fact that it can be converted to the quinazolon by boiling with concentrated hydrochloric acid or by sublimation. We are now endeavoring to prepare sufficient of this material to determine its structure, in the hope that it may throw considerable light upon the course of this interesting synthesis.

PREPARATION OF DERIVATIVES OF 2-METHYL-4-KETODIHYDROQUINAZOIIN.

Three sets of derivatives were prepared for purposes of comparison, one from quinazolon obtained by Bischler's synthesis, another from quinazolon obtained by Niementowski's synthesis, and a third set from our own product. An examination of similar derivatives in the three sets showed them in every case to be identical in all points irrespective of the source of the quinazolon.

Hydrochloride.-Prepared by boiling the free base, or its alkaline salts, with excess of concentrated hydrochloric acid. As the solution cools the hydrochloride crystallizes out in long trans- 
parent needles, often of a decided yellowish cast and with a strong greenish fluorescence. These needles sublime without decomposition or dissociation, and do not break up at $336^{\circ} \mathrm{C}$. as reported by Niementowski.'

Chlorplatinate. - By the addition of platinic chloride to a hot solution of the hydrochloride the chlorplatinate gradually separates on cooling in coarse red crystals, which can be recrystallized from water. Frequently unchanged hydrochloride will persistently separate with the cilorplatinate even after prolonged boiling with excess of platinum chloride.

$$
\begin{aligned}
& \begin{array}{c}
\text { Calculated for } \\
\left(\mathrm{C}_{9} \mathrm{H}_{8} \mathrm{~N}_{4} \mathrm{O} . \mathrm{HC}\right)_{3} \mathrm{PtCl}_{4} \text {. I. Found. }
\end{array} \\
& \mathrm{Pt} \ldots \ldots \ldots \ldots \ldots \ldots \ldots \ldots \ldots \ldots \ldots \ldots+26.6 \mathrm{r} \quad 26.62 \quad 26.7 \mathrm{~s}
\end{aligned}
$$

Nitratc. - When the free base is boiled with an excess of nitric acid ( $1: 4$ ), and the solution allowed to cool, the nitrate separates in white needles, which decompose at about $185^{\circ} \mathrm{C}$. Niementowski found his product to decompose at $195^{\circ} \mathrm{C}$.

Chromate.-This salt was prepared both by the addition of potassium chromate to a solution of the hydrochloride, and also by heating the free base with chromic anhydride. It forms yellow crystals, beginning to blacken at $176^{\circ} \mathrm{C}$. rather than at I $82^{\circ} \mathrm{C}$. as reported by Niementowski.

$$
\begin{aligned}
& \text { Calculated for } \\
& \mathrm{C}_{9} \mathrm{H}_{8} \mathrm{~N}_{2} \mathrm{OCC \textrm {CrO } _ { 3 }} \text {. Found. } \\
& \text { Cr............................. } 20.00 \quad 19.4 \mathrm{I}
\end{aligned}
$$

Methyl Ether.-Equal molecules of 2-methyl-4-ketodihydroquinazolin, potassium hydroxide, and methyl iodide are dissolved in alcohol, and the mixture heated several hours on the waterbath with a return condenser. The alcohol is driven off, and the residue crystallized from water. It then forms white needles, melting at $71^{\circ} \mathrm{C} .\left(72^{\circ} \mathrm{C}\right.$. corr. $)$ in the hydrated condition, and at $109^{\circ}-\mathrm{I}^{\circ} \mathrm{C}$. ( $110^{\circ}-\mathrm{III}^{\circ} \mathrm{C}$. corr. ) when anhydrous, thus identifying it with the $\beta, \gamma$-dimethyl- $\Delta$-pseudoxyquinazoline of Weddige, ${ }^{2}$ and proving conclusively the structure of the original 2-methyl-4-ketodihydroquinazolin, for the isomeric pheno-2methylhexadiazen(2)on(4) yields a dimethyl derivative melting at $199^{\circ} \mathrm{C}$. The structure of these isomeric dimethyl derivatives is as follows:

1 Ber. d. chem. Ges., $29,1360$.

2 J.prakt. Chem. [2], 36, 15 I. 


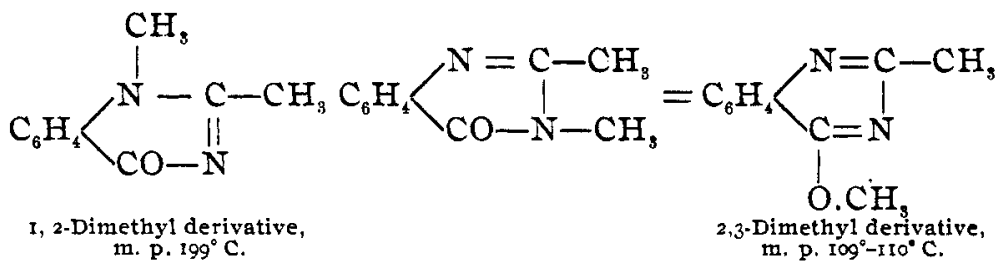

It seems most likely, in view of recent work upon similar compounds, that the 2-methyl-4-ketodihydroquinazolin reacts with alkalies in its pseudo or enolic form, and that the dimethyl derivative mentioned above contains the second methyl group attached to oxygen and not to nitrogen, thus giving an ether of a true methyl quinazolin. This would also explain why the 2,3 -dimethyl derivative has a melting-point so much lower than its isomer, for in the 2-methyl-4-ketodihydroquinazolin compound with the double bond at (2) the carbonyl is para to the imido group, and it could not therefore so easily pass into a pseudoenolic form.

\section{SYNTHESIS OF 2-METHYI-4-KETODIHYDROQUINAZOLIN FROM ACETYLANTHRANILIC ACID.}

Acetylanthranilic Acid.-This was prepared by the method of Jackson, ${ }^{1}$ from anthranilic acid and acetic anhydride. Anthranilic acid was boiled for three hours with twice the theoretical amount of acetic anhydride. On cooling nothing separated, so the mixture was precipitated by pouring into water, the mass then warmed slightly to decompose any excess of anhydride, and the precipitate filtered out and washed. This precipitate was next dissolved in ammonia water, reprecipitated by hydrochloric acid, the precipitate filtered out and crystallized from water, when it formed plates melting at $182^{\circ}-184^{\circ} \mathrm{C}$. Occasionally it separated in a gelatinous mass on crystallization, showing a slightly lower melting-point $\left(181^{\circ}-183^{\circ} \mathrm{C}\right.$.), due possibly to difficulty in getting it perfectly dry.

In all cases, a small amount of the precipitate obtained by the addition of hydrochloric acid to the ammoniacal solution refused to dissolve in boiling water. This insoluble portion was separated and crystallized from glacial acetic acid, yielding fine white needles, melting at $221^{\circ}-223^{\circ} \mathrm{C}$. This is probably the diacetyl

1 Ber. d. chem. Ges., $34,886$. 
derivative, but not enough was obtained for further investigation. Jackson, ${ }^{1}$ reports similar results in his preparation of the acetylanthranilic acid.

Diacetylanthranilic Acid.-Bedson ${ }^{2}$ states that when acetic anhydride and anthranilic acid are boiled together for some time under a return condenser the mixture solidifies on cooling to a crystalline mass of diacetylanthranilic acid. We have been unable to confirm this, as was the case apparently with Jackson also.

Anthranilic acid was boiled for several hours with acetic anhydride under a return condenser, but nothing separated on cooling. On addition of water a precipitate was obtained which, on recrystallization, proved to be impure monacetylanthranilic acid, melting at $175^{\circ}-185^{\circ} \mathrm{C}$. Another portion of anthranilic acid was heated with acetic anhydride until all excess of anhydride had been driven off. The residue was then dissolved in alcohol, the solution bone-blacked and evaporated, leaving a tarry mass from which hot benzene extracted a substance melting at $I 7^{\circ}-182^{\circ} \mathrm{C}$. on recrystallization, and which was evidently only impure monacetylanthranilic acid. Monacetylanthranilic acid was then boiled for ten hours with acetic anhydride, decomposition apparently setting in at this point, for when the mass was poured into water it produced a yellow milky solution with much tar.

The effect of pressure was next tried. Five grams of anthranilic acid, $9 \mathrm{cc}$. of acetic anhydride, and ro cc. glacial acetic acid, were heated together in a sealed tube for five hours at $160^{\circ}-170^{\circ}$ C. The contents of the tube then appeared liquid, and no pressure was detected on opening the tube. The excess of acetic acid and anbydride was removed by distillation, and the residue left in a desiccator over potassium hydroxide, where it gradually solidified to a crystalline mass, some of which recrystallized from benzene melted at $I 80^{\circ}-182^{\circ} \mathrm{C}$. and proved to be the monacetyl derivative again. We have, therefore, failed to get any appreciable amount of diacetylanthranilic acid by the methods employed.

Acetylanthranilic Acid and Acetonitrile.-Five grams of acetylanthranilic acid and $7 \mathrm{cc}$. acetonitrile were heated together in a sealed tube for four and a half hours at $220^{\circ}-210^{\circ} \mathrm{C}$. The tube

1 Loc, cit.

2 J. Chem. Soc., 37, 756 . 
was then filled with needle crystals and a dark brown liquid. No pressure was evident upon opening the tube. The liquid was decanted carefully from the crystals and the latter washed with dilute sodium carbonate solution, to remove unchanged acid, etc. The residual crystals dissolved in alcohol, bone-blacked, and the solution evaporated, yielded coarse needles melting at $232^{\circ}-236^{\circ} \mathrm{C}$. and readily identified with the 2 -methyl-4-ketodihydroquinazolin prepared by the methods already mentioned.

To prove that no acetyl derivative of the quinazolon was produced in this reaction, 0.5 gram of the quinazolon was boiled for one hour with $5 \mathrm{cc}$. acetic anhydride, and on cooling long needles separated exactly similar to those obtained from the above reaction. That these were really only the original quinazolon was shown by the molecular weight determination, by the freezingpoint method, with glacial acid as the solvent :

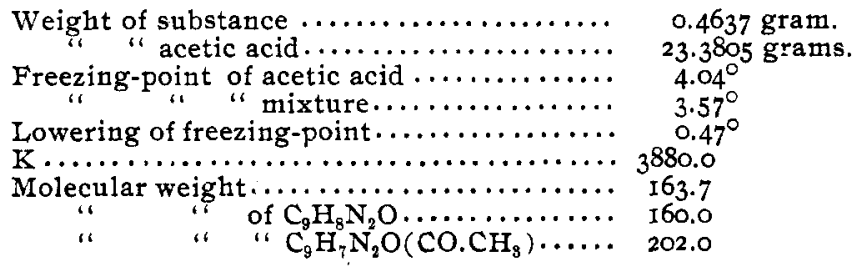

Acetyl chloride was found to have no action upon the quinazolon under ordinary conditions.

The experiments with anthranilic nitrile, acetylanthranilic nitrile, and similar orthoaminonitriles, form the subject of another paper.

In conclusion, then, the following new syntheses of 2-methyl4-ketodihydroquinazolin have been discovered:

r. By heating orthoamino acids, or their acyl derivatives, with nitriles.

2. By heating orthoaminonitriles, or their acyl derivatives, with acids.

The extension of these syntheses to other acids and nitriles is now under way. We are also studying the action of nitriles upon $\alpha$ - and $\beta$-amino acids and their nitriles both aliphatic and aromatic, as well as the action of nitriles upon other classes of orthosubstituted acids. 